\title{
Cuba, Vietnã, China: O retorno da NEP*
}

\author{
Bruno Casati* $^{* *}$
}

\section{Resumo}

As mudanças atuais nas economias socialistas de Cuba, Vietnã e China à luz da Nova Política Econômica (NEP) teorizada por Lenin.

Palavras-chave: Socialismo; NEP; Cuba; Vietnã; China.

Cuba, Vietnam, China: The NEP is back

\begin{abstract}
The current transformations in the socialist economics of Cuba, Vietnam and China in light of Lenin`s New Economic Policy (NEP).
\end{abstract}

Key words: Socialism; NEP; Cuba; Vietnam; China.

Frequentemente se escuta dizer que o comunismo no mundo está morto e sepultado. E, quando alguém tenta modestamente falar: "Mas olha que na China, no Vietnã, em Cuba..." isto é irascivelmente liquidado com frases do tipo: "Aqueles já são países capitalistas, só que lhes falta aquela liberdade que nós temos". O bonito (ou o feio) é que tais respostas, expressões do senso comum, veem seja da direita como da pálida esquerda reformista. E não

* Publicado originalmente em Gramsci Oggi - Rivista di Politica e di Cultura della Sinistra di Classe. Junho de 2012, p. 22-3. Tradução e resumos de Marcos Aurélio da Silva, Professor dos cursos de graduação e pós-graduação em Geografia da UFSC. Leram as primeiras versões do texto traduzido a doutoranda Leila Beltrão e a Prof $^{\text {a }}$ Gerusa Maria Duarte, a quem o tradutor agradece as críticas e sugestões.

Presidente do Circolo Culturale Concetto Marchesi de Milão

Geosul, Florianópolis, v. 28, n. 55, p 181-187, jan./jun. 2013 
CASATI, B. Cuba, Vietnã, China: O retorno da NEP.

que, uma e outra, tenham adotado os argumentos sempre caros aos trotskistas. A verdade é que ninguém mais estuda, conhece, examina a fundo, mesmo na era da internet; vivemos o tempo da superficialidade, senão na ignorância informada. Mas há uma segunda verdade oculta neste confronto: para a direita, como é óbvio, e para a esquerda, como não deveria sê-lo (óbvio), em suma para todos os coveiros do comunismo, o que vivemos, na Itália, por exemplo, é o melhor dos mundos possíveis, onde, no máximo, a esquerda pode levantar a voz, mas na web, reivindicando direitos ou exercitando-se na retórica dos bens comuns. E é por esta razão de fundo - não há nenhuma sociedade para transformar radicalmente - que, no Ocidente, é preciso ora esconder ora desinformar sobre os processos reais de transformação em curso atualmente no planeta. Processos que, fossem conhecidos, diríamos que outro mundo é certamente possível, aliás, está em construção, com as características do socialismo, entendendo por socialismo a fase de transição da forma capitalista àquela comunista. Conceito válido também quando a forma capitalista é precedida da opressão colonial e da posterior luta de libertação.

China, Vietnã, Cuba são hoje os países e os povos imersos nestes processos de transição. E, cada um com as próprias peculiaridades, procura, de um lado, não repetir os erros que levaram não à derrota do comunismo, mas àquela forma assumida na União Soviética com o chamado "Socialismo Real", e de outro, redescobrir e reatualizar aquelas intervenções que, nos anos imediatamente posteriores à Revolução de Outubro, se fizeram necessárias para salvar a mesma Revolução. Aquelas intervenções, então inscritas no projeto da "Nova Política Econômica" (a NEP) são, ao menos na opinião de quem escreve, a linha de conduta dos que hoje estão construindo o socialismo. Cada um com a sua NEP.

Mas o que foi a NEP naquele ano de 1921 em que se iniciava? Foi o conjunto de ideias e de ações concretas com os quais se procurou sair dos vastos problemas com que se defrontava a imensa Rússia após a I Guerra Mundial, após o Outubro e após a Guerra Civil para afirmar a revolução: a carestia; os deslocamentos 
CASATI, B. Cuba, Vietnã, China: O retorno da NEP.

de massas incalculáveis de refugiados e órfãos; a não resolvida questão fundamental dos camponeses, que eram a maioria do povo, enquanto os proletários industriais eram a minoria; as greves dos operários, como a de Petrogrado, ou as revoltas dos soldados, como na fortaleza marítima do Kronstadt; o forte bloqueio dos países capitalistas. Era esta a crise que poderia arrastar consigo a Revolução.

Com efeito, a NEP, numa primeira leitura simplificada, foi a liberalização do pequeno comércio privado - "Se façam circular as mercadorias" - o lançamento da cooperação, o início de um sistema de economia mista (o qual, porém, abriu caminho ao "NEPMAN", ambígua figura de capitalista que se movia em uma economia controlada pelos comunistas). Mas a NEP foi muito mais. Tratou-se de uma revisão profunda, sobretudo teórica, uma virada, que após a tomada armada do poder, levou ao socialismo como uma transição, e em um percurso lento. Disse Lenin a esse propósito: "É preciso armar-se da salutar desconfiança em relação a cada progresso mais rápido, em relação a qualquer jactância... a coisa mais nociva é a pressa" (V. I. Lenin, Opere Complete, v. 33, p. 446). Sempre a esse propósito comenta Boffa: "São formulações que deixam entrever aquilo que, segundo uma categoria gramsciana, é a passagem da 'Guerra de Movimento' à 'Guerra de Posição', se estivesse delineado no pensamento de Lenin não só a luta internacional, mas também a evolução interna do País" (Giuseppe Boffa, Storia dell'Unione Sovietica, 1917-1941, p. 239).

E aquela não foi uma revisão simples. Mesmo entre os bolcheviques circulava a ideia de que a NEP fosse uma rendição, assim como, entre os adversários da Revolução, fosse a admissão de sua falência. Portanto, a NEP foi o resultado de uma batalha política cerrada. Em todo o caso, com a NEP, se abrandaram os focos de rebelião e se experimentou a primeira forma de aliança entre os operários e os camponeses, aquela da qual dependia o destino mesmo do poder comunista na Rússia. Nesse sentido, a NEP foi também a primeira ação de uma política de paz, não militar, passível de a Revolução aplicar. 
CASATI, B. Cuba, Vietnã, China: O retorno da NEP.

Mas a NEP se encerra no ano de 1928, mesmo se Stalin continue a falar dela até 1936. Porque é de 1928 o abalo - quando foram derrubadas - das atividades privadas estrangeiras e não estrangeiras, e quando foram abolidos os contratos que consentiam dar em arrendamento as empresas. O pequeno comércio não desaparece, mas imerge na clandestinidade e o famoso Nepman é posto no mesmo plano do Kulak, com as consequências que se seguem. Em compensação, se lança o primeiro plano quinquenal e se abrem grandes canteiros da indústria pesada. A transição da NEP é bloqueada. Retorna o comunismo de guerra. E a guerra se avizinha de fato. Fala-se muito dos erros da União Soviética. O mais grave, talvez, tenha sido aquele de não recuperar no após guerra - alguns tentaram fazê-lo - o percurso interrompido da transição anterior, não ter reproposto uma nova NEP. Além disso, esquece-se que são grandes os méritos da URSS: ter derrotado o nazifascismo pagando o preço de um elevado número de vidas humanas; ter concretamente sustentado todos os povos (com o sacrifício do seu) que se batiam para superar o tacão de ferro do colonialismo; ter fornecido apoio à luta dos trabalhadores do Ocidente, aos quais, mesmo porque existia a URSS, a burguesia fazia (limitadas) concessões que, hoje, até porque não há mais no Oriente um forte competidor político, vêm sendo todas retiradas (e, na Itália, se retiram com juros).

Quem se ocupa da NEP hoje e tipifica a própria transição ao socialismo segundo a história, as condições, as características do próprio povo são precisamente os comunistas chineses, cubanos, vietnamitas e, por aspectos que caberia pesquisar, as primaveras latino-americanas onde se constroem áreas de mercado não capitalista. Em suma, se abriram hoje no mundo, sem intenções de ofender os Estados Unidos e os nossos coveiros do comunismo, os laboratórios da multipolaridade, que estão construindo, ou se aproximando do socialismo. E dois bilhões de pessoas seguem nesta estrada.

- O Vietnã, por exemplo, abre o seu laboratório só em 1991. Porque primeiro, o povo, já exausto da Guerra de Libertação que 
CASATI, B. Cuba, Vietnã, China: O retorno da NEP.

termina em 1975 com a expulsão dos americanos de Saigon, teve de retomar as armas com o Camboja. Ao término da operação militar a economia do país estava devastada. A sua taxa de crescimento era a mais baixa em relação aos outros países asiáticos. Depois a virada, a abertura aos capitais estrangeiros que acorrem ao país não só pelo baixo custo da mão de obra, mas pela estabilidade política associada a um país dirigido pela astúcia de um Partido Comunista que, precisamente, marcha com sucesso na estrada da sua "Nova Política Econômica".

- Da grande China se escreve muito, porém sempre inadequadamente. Aqui nos interessa apenas sublinhar como a China havia se tornado, ao fim dos anos quarenta, o país mais pobre do mundo pela agressão e anexação predatória do Ocidente. E é esta a situação que encontram os comunistas em 1949 quando, derrotados os nacionalistas, tomam o poder.

Hoje a China é a segunda economia do planeta. Realizou-se o maior salto econômico jamais visto na história da humanidade.

A virada, a NEP chinesa, é lançada por Deng Xiao Ping em 1979 com um conjunto de medidas — o "socialismo de mercado" - que respondiam a uma palavra de ordem: "Primeiro encher os celeiros, depois pensar as fórmulas". Encaminham-se assim as "Quatro Modernizações", que se apoiam sobre um único tipo de intercâmbio: "Tu Ocidente vem investir na China e nos traz conhecimento. Eu, China, te ajudo, te ponho a disposição a minha mão de obra a baixo custo, assim dou o de comer ao meu povo e, neste meio tempo, acumulo saber." O resultado da NEP chinesa está hoje aos olhos de todos, mesmo se muitos só olham para o Dalai Lama e para alguns blogueiros dissidentes (bem curiosos estes dissidentes chineses que podem falar, escrever, dar entrevista!). Em todo caso é o Partido Comunista Chinês que, hoje, consciente da contradição implícita em uma corrida demasiado acelerada para a prosperidade, convida a considerar a China ainda como "País em via de desenvolvimento, ainda hoje colocado na fase primitiva do socialismo" (dispositivo final do XVII Congresso do PCC). 
CASATI, B. Cuba, Vietnã, China: O retorno da NEP.

Mais interessante, e menos notada, é a virada que vem hoje inscrita na economia cubana. Cuba é um país único no mundo: não existe outro país que tenha resistido ao assédio posto pelos EUA, que é o mais longo jamais estabelecido na história moderna. Cuba tem resistido ao "bloqueio" como aos cinco furacões que varreram a ilha nos últimos dez anos, assim como resistido ao terrorismo que assassinou 4.000 cidadãos cubanos. Cuba, sobretudo, soube resistir com o "Período Especial", quando, há mais ou menos vinte anos, a União Soviética, que então se dissolvia, interrompeu repentinamente as relações comerciais exclusivas que tinha com Havana. Cuba importava mercadorias da União Soviética, mas também suas limitações, e o sabia, tanto que alguns anos antes, em 1986, havia iniciado a campanha da "Retificação dos Erros", com que se propunha reduzir os aparatos burocráticos e descentralizar poder aos territórios. O "Período Especial", porém, retarda aquele processo que, só hoje, é vigorosamente relançado com o VI Congresso de Abril de 2011, data do 50 aniversário da vitória de Playa Girón. Nele se aprovam uma série de reformas voltadas a salvar a economia e a revolução. A NEP cubana é um projeto em que as linhas mestras foram discutidas por bem uns nove (entre onze) milhões de cidadãos, e onde se combinam elementos fundamentais de socialismo com elementos de capitalismo. E é o Partido Comunista que controla as "Grandes Estratégias" - as bases da economia, da empresa pública ou privada, cubana ou estrangeira - com o objetivo do desenvolvimento econômico. Assim, as reformas anunciadas e depois arrefecidas no "Período Especial", são retomadas, reconhecendo que nem todos os limites são imputáveis ao bloqueio: é preciso então dar força à pequena empresa e ao artesanato, é preciso reduzir o peso do enorme aparato estatal improdutivo, é preciso atrair (como Vietnã e China) investimentos externos. E o caminho através do socialismo prossegue com esta mudança de velocidade e estrutura.

Que síntese se pode tirar do nosso Observatório se se olha com honestidade tanto para estes laboratórios (e não examinei os latino-americanos) quanto para a situação da Itália e da Europa? 
CASATI, B. Cuba, Vietnã, China: O retorno da NEP.

Enquanto na Itália, na Europa e alhures, estamos no interior de uma fase de declínio do capitalismo histórico (que pode sempre revitalizar-se), em outras partes do planeta se está redefinindo um novo centro de gravidade da economia e construindo uma sociedade de mercado não capitalístico. O desafio perdido da União Soviética recomeça noutro terreno. Terá sucesso este desafio? Pode tê-lo se, à luta dos povos que se batem pela própria prosperidade na via do socialismo, se associar a luta para inserir elementos de socialismo nos países onde domina o capitalismo. Após a Libertação, nos provara isto o Partido Comunista Italiano e Togliatti, para quem o eixo de uma transição socialista na Itália era a Constituição Republicana. E o corroborou Berlinguer, mas foi derrotado pelo governismo melhorista do seu próprio partido. Recuperar estes temas não é o suplício de Sísifo, mas a nossa tarefa.

\section{Referências bibliográficas}

Boffa, Giuseppe. Storia dell'Unione Sovietica. 1917-1941 Lenin e Stalin. Dalla Rivoluzione alla Secunda Guerra Mondiale. Vol. 1. Milano: Mondadori, 1976.

Lenin, Vladimir Ilyich. Opere Complete. Vol. 33. Roma: Riuniti, 1955. 